Bull. Chem. Soc. Ethiop. 2019, 33(1), 11-20.

ISSN 1011-3924

(C) 2019 Chemical Society of Ethiopia and The Authors

Printed in Ethiopia

DOI: https://dx.doi.org/10.4314/bcse.v33i1.2

\title{
REVERSED FLOW-INJECTION METHOD FOR ESTIMATION OF CHLORPROMAZINE IN PHARMACEUTICALS AND URINE SAMPLES USING CHARGE-TRANSFER COMPLEXATION
}

\author{
Fathalla Belal ${ }^{1}$, Hind $\mathrm{Hadi}^{2 *}$ and Mariam Jamal ${ }^{2}$ \\ ${ }^{1}$ Department of Analytical Chemistry, Faculty of Pharmacy, University of Mansoura, 35516, \\ Mansoura, Egypt \\ ${ }^{2}$ Department of Chemistry, College of Science, University of Baghdad, Baghdad, Iraq
}

(Received September 15, 2018; Revised January 20, 2019; Accepted January 27, 2019)

\begin{abstract}
A simple, automated and sensitive reversed flow-injection analysis (rFIA) method for the determination of chlorpromazine hydrochloride (CLP) in pharmaceutical formulations and human urine samples is described. The automated method is based on the formation of charge-transfer complex between CLP (donor) with new reagent (an acceptor) used for the first time namely, 4,4'-tetramethyl-diaminodiphenylmethane (TDM) in the presence of $\mathrm{K}_{2} \mathrm{~S}_{2} \mathrm{O}_{8}$ as an oxidant. An intense blue-colored product, which gave a maximum absorbance at 604 $\mathrm{nm}$, was formed immediately at room temperature. The various chemical and physical conditions that affected the reaction have been studied. The calibration curve was rectilinear within the concentration range $1-45 \mu \mathrm{g} / \mathrm{mL}$ and the detection and quantification limits of 0.72 and $2.40 \mu \mathrm{g} / \mathrm{mL}$ respectively with a sample through put of 80 sample/hour. The proposed procedure was applied successfully for the estimation of CLP and the results obtained were favorably compared with those given by a reference method, and there was no significant difference between the obtained results, regarding accuracy and precision at the $95 \%$ confidence level.
\end{abstract}

KEY WORDS: Chlorpromazine, Flow injection analysis, Charge-transfer complexation

\section{INTRODUCTION}

Chlorpromazine hydrochloride is the most important compound in the large group of phenothiazine derivatives. It is widely used as antipsychotropic, anticholinergic, and antihistaminic drug [1]. Like other phenothiazines, it is easily oxidized in acid medium under the action of various oxidizing agents leading to the formation of intensely colored oxidation products. The official methods for its determination listed in the British Pharmacopoeia (BP) and US Pharmacopoeia (USP), consist in the non-aqueous potentiometric titrimetry or spectrophotometry in the ultraviolet region $[2,3]$.

Several methods were reported for determination of CLP in dosage forms and biological samples, these methods involved spectrophotometric methods using several reagents such as Eriochrome cyanine R [4], Alizarin red S [5], and ferricyanide [6] were reported, but these methods either required a relatively a complexometric extraction steps [4, 5], or long heating time [6]. Other methods involved chromatography [7, 8], spectrofluorimetry $[9,10]$ and electrochemical methods [11-13]. However, all these methods involve sophisticated and expensive equipment or solvents and time-consuming. Recently, many reports have been published about the applications of flow technique for quantitative analysis. The aim of different kinds of flow injection methods is to analyze the maximum number of samples with a minimum amount of reagents, sample solution and analysis time [14]. Several flow injection analysis methods were employed for the determination of chlorpromazine together with spectrophotometry $[15,16]$, spectrofluorometry $[17,18]$, and chemiluminescence [19-21]. Some of these methods either require expensive or unavailable materials.

In the present work, a simple and sensitive double line rFIA-spectrophotometric method is proposed for the determination of CLP in pure and dosage forms and in spiked urine samples on

*Corresponding author. E-mail: hha3pharm @yahoo.com

This work is licensed under the Creative Commons Attribution 4.0 International License 
the basis of the charge-transfer reaction between CLP and TDM in the presence of potassium persulfate that gives blue species.

\section{EXPERIMENTAL}

\section{Instrumentation}

A digital double beam spectrophotometer Shimadzu UV-VIS 260 type (Shimadzu, KyotoJapan) was used for all the spectral and absorbance measurements of FIA procedures. The absorbance measurements were carried out using $1 \mathrm{~cm}$ path length of quartz flow matched cells (Cecil, $50 \mu \mathrm{L}$ internal volume). A peristaltic pump of six channels (Ismatec, LabortechnikAnalytic, type CH-8152, Glatbrugg Zurich-Switzerland) used for pumping the solutions of reagents. A 6-ways injection valve with different loops (Rheodyne, Altex 210, Supelco, USA) was used for injected samples. A flexible vinyl tubing $(0.8 \mathrm{~mm}$ i.d.) was used for the peristaltic pump, while tubes of Teflon material with an internal diameter of $0.5 \mathrm{~mm}$ was used at different lengths of reaction coil ( $\mathrm{RC})$. A double configuration flow-injection manifold is schematically shown in Figure 1. TDM was injected through the injection valve into a flowing stream propelled by the peristaltic pump containing potassium persulfate solution then mixed with the second stream that passes the drug. The solutions were mixed in reaction coil and the absorbance of the product was measured at $604 \mathrm{~nm}$.

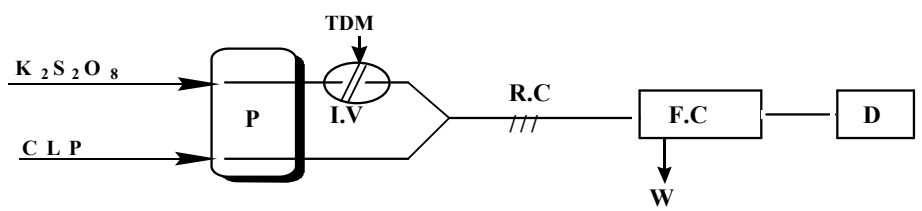

Figure 1. Manifold employed for a double line rFIA-Spectrophotometric determination of CLP by reaction with TDM in the presence of $\mathrm{K}_{2} \mathrm{~S}_{2} \mathrm{O}_{8}$, where: I.V, injection valve; R.C, reaction coil; P, peristaltic pump; F.C, flow cell; D, detector; W, waste.

\section{Reagents and materials}

The reagents grade materials were used throughout this work. Chlorpromazine hydrochloride (CLP), the working standard (purity of $99.9 \%$ ), was kindly supplied by the State Company for Drug Industries and Medical Appliances (SDI), Samarra, Iraq. Two generic versions each contains CLP as its active constituent (Largactil ${ }^{\circledR}, 25 \mathrm{mg}$ and $100 \mathrm{mg}$, Aleppo, Syria) were obtained from local markets. 4,4'-tetramethyl-diaminodiphenylmethane (TDM), potassium persulfate $(\mathrm{BDH})$ were used as received.

Chlorpromazine hydrochloride. A standard stock solution of $250 \mu \mathrm{g} / \mathrm{mL}$ chlorpromazine hydrochloride was prepared in $100 \mathrm{~mL}$ distilled water. The solution was kept in an ambercolored bottle and stored in a refrigerator. Working solutions were prepared by appropriate dilutions of the stock solution with distilled water.

4,4-Tetramethyl-diaminodiphenylmethane (TDM). The stock solution of $0.005 \mathrm{M}$ of TDM reagent (M.wt. $254.38 \mathrm{~g} / \mathrm{mol}$ ) was prepared by dissolving $0.1272 \mathrm{~g}$ of the reagent in $100 \mathrm{~mL}$ of ethanol. More dilute solutions were obtained from dilution using the same solvent.

Potassium persulfate. A stock solution of $0.5 \mathrm{M}$ was prepared by dissolving $13.516 \mathrm{~g}$ of potassium persulfate (M.wt. $270.32 \mathrm{~g} / \mathrm{mol}$ ) in the appropriate amount of warm water and made up to $100 \mathrm{~mL}$ with water. The working solution was prepared by dilution with distilled water. 
General FIA procedure

Working solutions of CLP in the range of $1-45 \mu \mathrm{g} / \mathrm{mL}$ were prepared from stock solution. A 100 $\mu \mathrm{L}$ portion of $0.002 \mathrm{M}$ of TDM was injected through the injection valve into the stream of 0.07 $\mathrm{M}$ potassium persulfate solution then mixed with a stream of $10 \mu \mathrm{g} / \mathrm{mL}$ of CLP; the streams were propelled by peristaltic pump with total flow rate of $3.56 \mathrm{~mL} / \mathrm{min}$ (Figure 1). The solutions were mixed in reaction coil of $50 \mathrm{~cm}$ and then the absorbance of blue product was measured at $604 \mathrm{~nm}$ and a calibration graph was plotted over the range cited above. Alternatively, the corresponding regression equation was derived. Optimization of conditions was carried out using $10 \mu \mathrm{g} / \mathrm{mL}$ of CLP.

Procedure for the preparation of solutions of tablets

Tablets were accurately weighted and finely powdered. A specific amount of the powder equivalent to $0.025 \mathrm{~g}$ of the pure drug, was transferred into a $100 \mathrm{~mL}$ calibrated flask, then dissolved with distilled water and completed to mark with the same solvent to obtain final concentration of $250 \mu \mathrm{g} / \mathrm{mL}$. The flask with its contents was shacked well and filtered. Further appropriate solutions of pharmaceutical preparations were made by simple dilution using distilled water. The proposed method was then applied. The nominal content of the tablets was calculated using the regression equation obtained from previously plotted calibration graph.

Spiked urine samples preparation

Urine samples were collected from healthy volunteers and kept frozen until use after gentle thawing. The spiked urine samples were prepared according to previous published work [22] by dissolving of $6.25 \mathrm{mg}$ of standard CLP in $5 \mathrm{~mL}$ distilled water. Subsequently a $12.5 \mathrm{~mL}$ aliquot of urine was transferred into $25 \mathrm{~mL}$ volumetric flask and diluted with distilled water to attain a concentration of $250 \mu \mathrm{g} / \mathrm{mL}$ of the spiked CLP. Blank solution was prepared simultaneously. Further appropriate solutions for rFIA procedure were made by simple dilution using distilled water. The nominal content of the samples were calculated using the corresponding regression equation.

\section{RESULTS AND DISCUSSION}

\section{Absorption spectra}

This study examined the parameters affecting mainly the sensitivity and stability of the colored product resulting from the charge-transfer complexation between CLP and TDM in the presence of $\mathrm{K}_{2} \mathrm{~S}_{2} \mathrm{O}_{8}$. The effect of the chemical and physical parameters was studied by changing one parameter at a time and keeping the others fixed. Figure 2 represents the absorption spectrum of the reaction product of CLP with TDM under the optimized reaction conditions.

Optimization of the FIA system conditions

Initial studies were directed towards the optimization of the experimental conditions for FIA system.

\section{Effect of the chemicals and physical variables}

Effect of chemical variable (concentration of reagent and oxidant) and the physical parameters like the flow rate, length of reaction coil and the injected volume were studied. 


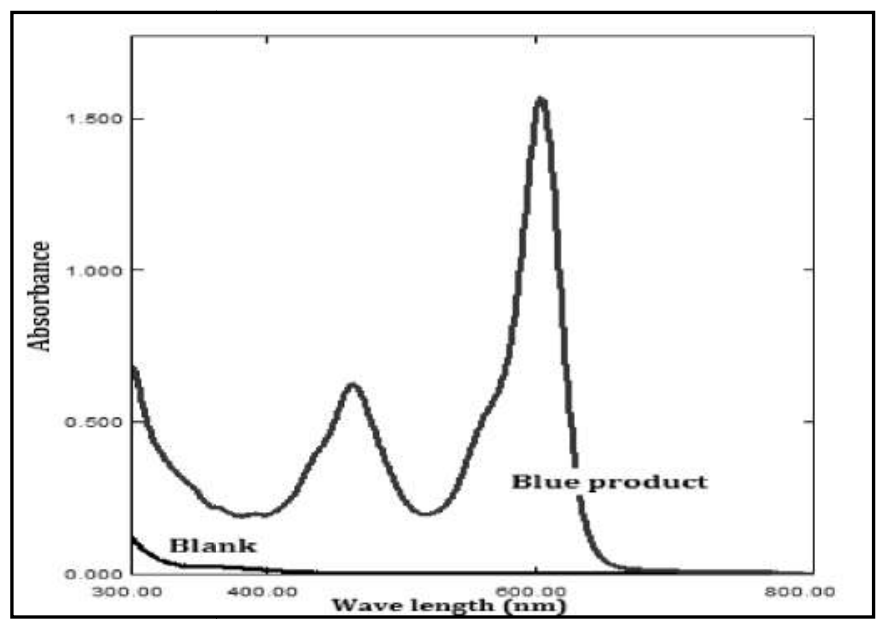

Figure 2. Absorption spectrum of the reaction product CLP $(25 \mu \mathrm{g} / \mathrm{ml})$ with TDM $/ \mathrm{K}_{2} \mathrm{~S}_{2} \mathrm{O}_{8}$.

\section{Effect of reagent and oxidant}

Optimum concentration of the reagent (TDM) was studied by injecting different concentrations (from 1 to $5 \mathrm{mM}$ ) using injection valve. The results in (Figure 3a) indicated that the $2 \mathrm{mM}$ gave the highest value of absorbance and good repeatability Because TDM is used as an acceptor, an equivalent concentration of this reagent was used and for this reason $2 \mathrm{mM}$ was chosen.

$\mathrm{K}_{2} \mathrm{~S}_{2} \mathrm{O}_{8}$ found to be a useful oxidizing agent for charge transfer reaction, other oxidants like $\mathrm{NaIO}_{4}, \mathrm{KIO}_{3}, \mathrm{FeCl}_{3}$ and $\mathrm{Ce}\left(\mathrm{SO}_{4}\right)_{2}$ have also been tested, but there was no reaction obtained with these oxidants. Different concentrations of $\mathrm{K}_{2} \mathrm{~S}_{2} \mathrm{O}_{8}$ were also studied in the range of 0.01 to 0.2 $\mathrm{M}$. Figure $3 \mathrm{~b}$ referred to increase the value of absorbance with increasing the concentrations of oxidant up to $0.07 \mathrm{M}$ and after this concentration the value of absorbance decreased. As a result, $0.07 \mathrm{M}$ was chosen for the subsequent experiments.

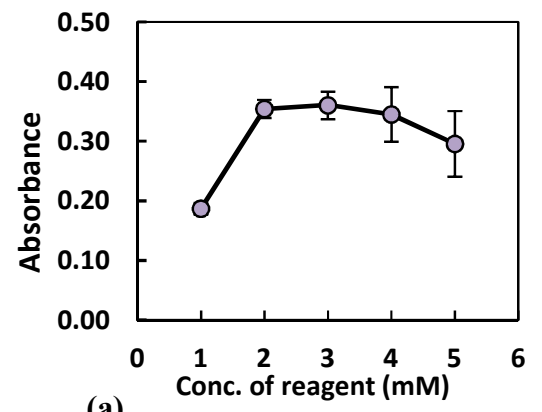

(a)

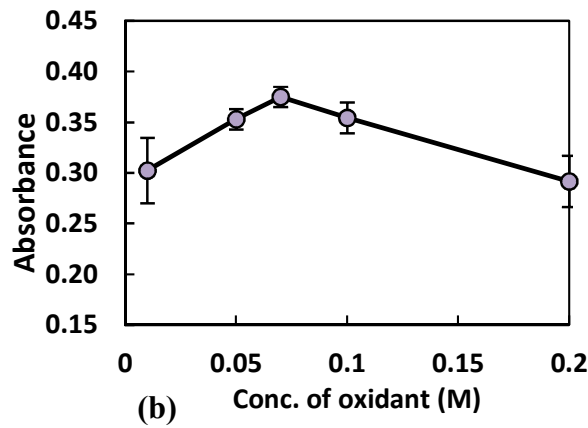

(b)

Figure 3. Effect of (a) concentration of TDM and (b) concentration of $\mathrm{K}_{2} \mathrm{~S}_{2} \mathrm{O}_{8}$ on the absorbance of reaction product. 
Effect of reaction coil length and injected volume

Optimum length of reaction coil was studied in range of 10-100 $\mathrm{cm}$. An acceptable repeatability with best absorbance value was gained from the length of $50 \mathrm{~cm}$. Absorbance decreased upon using a coil length of more than $50 \mathrm{~cm}$ (Figure 4a), this may be due to increased sample dilution and dispersion [23], consequently the $50 \mathrm{~cm}$ length was chosen as optimum one.

Also various volumes of injector loop were tested in this study. Effect of injected reagent volume was studied in the range of $75-200 \mu \mathrm{L}$. The values of absorbance increased with the increase of the injected volumes up to $100 \mu \mathrm{L}$ and then decreased. Therefore, a $100 \mu \mathrm{L}$ was used in the next experiments (Figure $4 b$ ).
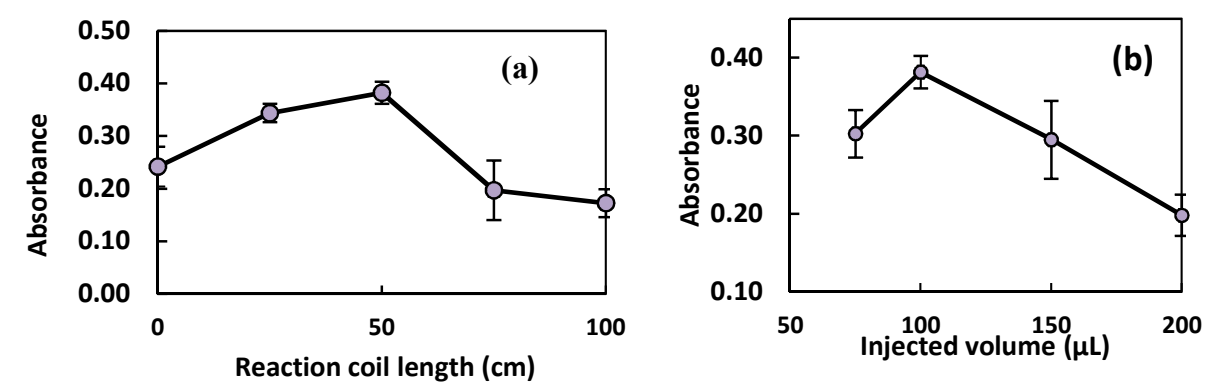

Figure 4. Effect of (a) length of reaction coil and (b) injected sample volume on the absorbance of reaction product.

Effect of optimum total flow rate

As mentioned previously, the sensitivity and sampling rate robustly depends on the value of flow rate. Optimum flow rate was studied using a range of rates ranging from 2.13 to 4.76 $\mathrm{mL} / \mathrm{min}$. Figure 5 demonstrates that a flow rate of $3.56 \mathrm{~mL} / \mathrm{min}$ gave the highest absorbance value. The adopted reaction is preferred a high flow rate, because of its highly instability, and the flow rate more than $3.56 \mathrm{~mL} / \mathrm{min}$ caused a decreased in absorbance because of the dispersion of sample zone, so it was selected throughout the method.

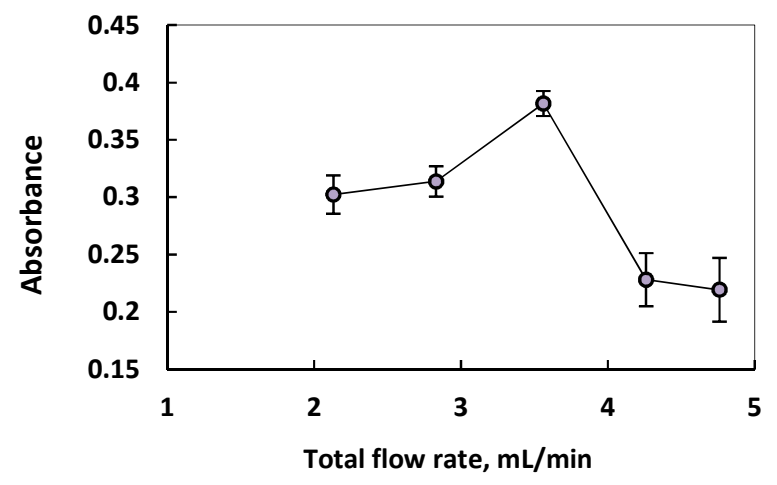

Figure 5. Effect of total flow rate.

Bull. Chem. Soc. Ethiop. 2019, 33(1) 


\section{Selected optimum conditions}

All the previous optimum values obtained from studies the chemical and physical variables on the reaction applied in rFIA system are summarized in Table 1.

Table 1. Optimum conditions.

\begin{tabular}{|c|c|c|c|c|c|}
\hline Variables & $\begin{array}{c}\text { Conc. of TDM } \\
(\mathrm{mM})\end{array}$ & $\begin{array}{c}\text { Conc. of } \\
\mathrm{K}_{2} \mathrm{~S}_{2} \mathrm{O}_{8}(\mathrm{M})\end{array}$ & $\begin{array}{c}\text { Reaction coil } \\
(\mathrm{cm})\end{array}$ & $\begin{array}{c}\text { Sample volume } \\
(\mu \mathrm{L})\end{array}$ & $\begin{array}{c}\text { Flow rate } \\
(\mathrm{mL} / \mathrm{min})\end{array}$ \\
\hline Studied range & $1-5$ & $0.01-0.2$ & $0-100$ & $75-200$ & $2.13-4.76$ \\
\hline Optimum value & 2 & 0.07 & 50 & 100 & 3.56 \\
\hline
\end{tabular}

\section{Sampling rate and dispersion of zone}

After optimizing all the manifold variables, and under these conditions, the sampling rate was calculated depending on time required from the injected reagent to reach to maximum absorbance (this time was found to be $30 \mathrm{~s}$ ) in addition to $15 \mathrm{~s}$ required for elution the zone, so the sampling rate was 80 sample/ hour for the proposed rFIA method.

Dispersion value was calculated using optimum conditions (Table 1) by comparing the signal obtained from ordinary injection with that of three streams flow system.

In the first stream, TDM of $0.002 \mathrm{M}$ is ejected through a stream (rather than injected) and the second stream containing $10 \mu \mathrm{g} / \mathrm{mL}$ of CLP, and the third a $0.07 \mathrm{M}$ of potassium persulfate (a continuous absorbance $\left(\mathrm{A}_{\mathrm{o}}\right)$ was obtained). In another experiment, the same concentration of TDM was injected via injection valve and then absorbance was measured $\left(A_{\max }\right)$. The obtained dispersion value $\left(\mathrm{D}=\mathrm{A}_{\mathrm{o}} / \mathrm{A}_{\max } ; \mathrm{D}=0.45 / 0.36=1.25\right)$ indicated that the dispersion is limited.

\section{Method validation}

The linearity of the calibration graph for present method was obtained by injecting a series of solutions of CLP $(1-45 \mu \mathrm{g} / \mathrm{mL})$ prepared from stock solution. A portion of TDM (100 $\mu \mathrm{L}$ of $0.002 \mathrm{M})$ was injected into the stream of $\mathrm{K}_{2} \mathrm{~S}_{2} \mathrm{O}_{8}$ solution $(0.07 \mathrm{M}$ and flow rate of 3.56 $\mathrm{mL} / \mathrm{min}$ ) and at $604 \mathrm{~nm}$ the absorbance of the blue dye was measured as summarized in Table 2 .

Table 2. Summary of optical characteristics.

\begin{tabular}{|l|l|}
\hline Parameter & Value \\
\hline$\lambda_{\max }(\mathrm{nm})$ & 604 \\
\hline Regression equation & Absorbance $=0.0185 \times$ Concentration +0.1589 \\
\hline Dynamic range $(\mu \mathrm{g} / \mathrm{mL})$ & $1-45$ \\
\hline Slope, $\mathrm{b}(\mathrm{mL} / \mu \mathrm{g})$ & 0.0185 \\
\hline Intercept, a & 0.1589 \\
\hline Correlation coefficient $\left(\mathrm{R}^{2}\right)$ & 0.9993 \\
\hline Percentage linearity, $\% \mathrm{r}^{2}$ & 99.86 \\
\hline Standard deviation of residuals $\left(\mathrm{S}_{\mathrm{y} / \mathrm{x}}\right)$ & $1.15 \times 10^{-2}$ \\
\hline Standard deviation of slope $\left(\mathrm{S}_{\mathrm{b}}\right)$ & $2.35 \times 10^{-4}$ \\
\hline Standard deviation of intercept $\left(\mathrm{S}_{\mathrm{a}}\right)$ & $5.98 \times 10^{-3}$ \\
\hline Sample through-put $\left(\mathrm{hr}^{-1}\right)$ & 80 \\
\hline LOD* $(\mu \mathrm{g} / \mathrm{mL})$ & 0.72 \\
\hline LOQ** $(\mu \mathrm{g} / \mathrm{mL})$ & 2.40 \\
\hline
\end{tabular}

$*$ LOD $=3 \times$ standard deviation of blank absorbance for 10 readings $/$ slope. ${ }^{* *} \mathrm{LOQ}=10 \times$ standard deviation of blank absorbance for 10 readings /slope. 


\section{Study of interferences}

In order to examine the selectivity of the method, the interference likely to be introduced from excipients was studied. A sample of pure CLP $(10.0 \mu \mathrm{g} / \mathrm{mL})$ spiked with 10 -fold excess concentration of selected three excipients were analyzed. The acceptable recovery values (98.4$99.7 \%$ ) demonstrated that, there were no interferences during the determination of CLP using proposed rFIA method.

\section{Stoichiometry of product and proposed mechanism}

The stoichiometry of product was studied using mole ratio method [24]. In mole ratio method (using optimum conditions) a stream was passed through the flow system, containing variable concentration of TDM $\left(5 \times 10^{-5}-5 \times 10^{-4} \mathrm{M}\right)$ and constant concentration of CLP $\left(2 \times 10^{-4} \mathrm{M}\right)$. The results obtained show that a 1:1 (TDM:CLP) was formed.

Generally the interactions between electron donors and acceptors are related to formation of intensely colored charge transfer complexes absorb radiation in the visible region $[25,26]$. The literature reported two methods based on charge transfer reaction for determination CLP as n-donor (from methylated nitrogen atom) with tetracyanoethylene, 7,7,8,8-tetracyanoquinodimethane [27] and xanthine dyes (fluorescein and erythrosin) [28] as acceptors. In addition it was previously reported that TDM reagent can be oxidized to unstable $\left(\mathrm{CH}_{3}\right)_{2} \mathrm{~N}^{+}=\left(\mathrm{C}_{6} \mathrm{H}_{4}\right)=\mathrm{CH}$ $\left(\mathrm{C}_{6} \mathrm{H}_{4}\right)-\mathrm{N}\left(\mathrm{CH}_{3}\right)_{2}$ [29-31]. The reaction product manually is not stable and therefore a FIA method was adopted. Depending on previous reports, the proposed mechanism may be postulated as shown in Scheme 1.

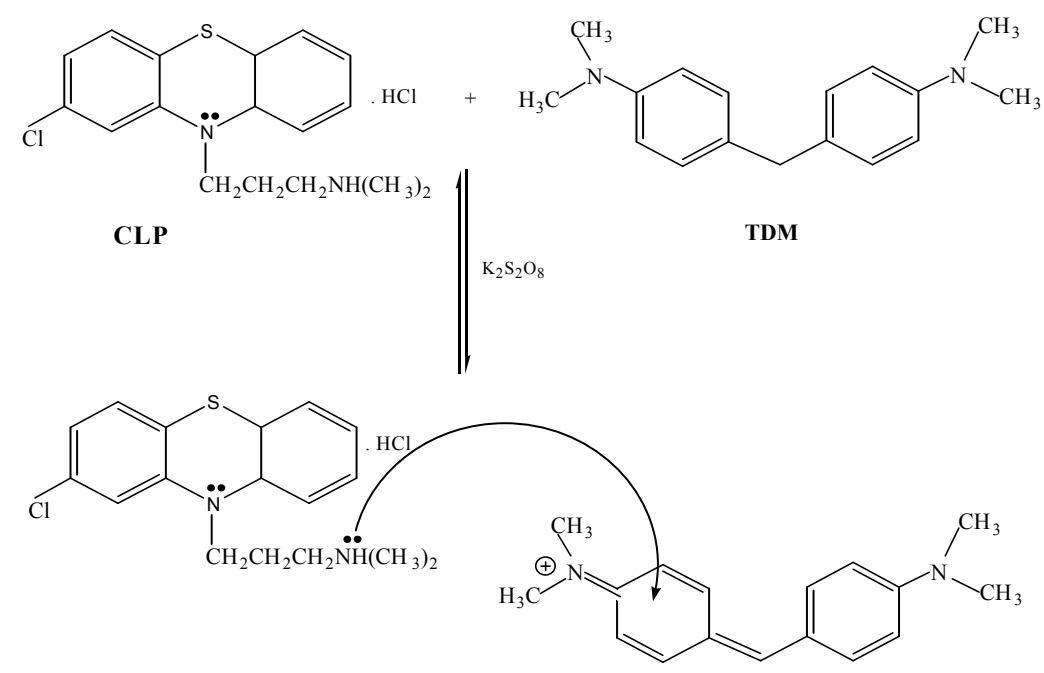

Scheme 1. Proposed reaction mechanism.

Application of the proposed method using pharmaceutical and urine samples

Two types of tablets containing CLP were analyzed under proposed method after preparing the solution of these tablets as mentioned in the previous sections. The proposed rFIA method was 
successfully applied for estimation CLP in tablets by the analysis of two different concentrations of two types of CLP tablets and the results are listed in Table 3.

In the direction of assessing the proficiency of the method, the obtained results were compared with those obtained upon applying standard USP method UV spectrophotometric method (Table 3). The statistical comparison between proposed and official methods using the student t- and F-test [32] indicated that the calculated values were less than the theoretical one, which referred to insignificant difference between both methods regarding accuracy and repeatability.

Table 3. Application of the proposed rFIA and official methods for estimation of CLP in tablets.

\begin{tabular}{|c|c|c|c|c|c|c|c|c|c|c|}
\hline \multirow[b]{2}{*}{ Dosage form } & \multicolumn{5}{|c|}{ rFIA method } & \multicolumn{5}{|c|}{ Official method [UV] } \\
\hline & $\begin{array}{l}\text { Taken conc. } \\
(\mu \mathrm{g} / \mathrm{mL})\end{array}$ & $\begin{array}{c}\text { Found } \\
\text { conc. } \\
(\mu \mathrm{g} / \mathrm{mL})\end{array}$ & $\begin{array}{c}\text { Recovery } \\
(\%)^{\mathrm{a}}\end{array}$ & $\begin{array}{l}\text { Mean } \\
\text { Rec. } \\
(\%)\end{array}$ & $\begin{array}{l}\text { RSD } \\
(\%)^{a}\end{array}$ & $\begin{array}{c}\text { Taken } \\
\text { conc. } \\
(\mu \mathrm{g} / \mathrm{mL})\end{array}$ & $\begin{array}{c}\text { Found } \\
\text { conc. } \\
(\mu \mathrm{g} / \mathrm{mL})\end{array}$ & $\begin{array}{c}\text { Recovery } \\
(\%)^{\mathrm{b}}\end{array}$ & $\begin{array}{l}\text { Mean } \\
\text { Rec. } \\
(\%)\end{array}$ & $\begin{array}{l}\text { RSD } \\
(\%)^{b}\end{array}$ \\
\hline \multirow{3}{*}{$\begin{array}{c}\text { Largactil }{ }^{\circledR} \\
\text { Tablets } \\
(25 \mathrm{mg} / \text { tablet }) \\
\end{array}$} & 20.0 & 20.1 & 100.5 & \multirow{3}{*}{100.9} & 0.29 & 50.0 & 50.7 & 101.4 & \multirow{3}{*}{101.2} & 0.44 \\
\hline & \multirow{2}{*}{30.0} & \multirow{2}{*}{30.4} & \multirow{2}{*}{101.3} & & \multirow{2}{*}{0.69} & 60.0 & 60.9 & 101.5 & & 0.40 \\
\hline & & & & & & 70.0 & 70.5 & 100.7 & & 0.27 \\
\hline \multirow{3}{*}{$\begin{array}{c}\text { Largactil }{ }^{\circledR} \\
\text { Tablets }(100 \\
\text { mg/tablet) }\end{array}$} & 20.0 & 19.5 & 97.5 & \multirow{3}{*}{99.3} & 0.30 & 50.0 & 50.1 & 100.2 & \multirow{3}{*}{100.2} & 0.21 \\
\hline & \multirow{2}{*}{30.0} & \multirow{2}{*}{30.3} & \multirow{2}{*}{101.0} & & \multirow{2}{*}{0.49} & 60.0 & 60.2 & 100.3 & & 0.10 \\
\hline & & & & & & 70.0 & 70.1 & 100.1 & & 0.24 \\
\hline Pure CLP & & & & 99.2 & & & & & 99.6 & \\
\hline $\begin{array}{l}\mathrm{t}(2.78)^{\mathrm{c}} \\
\mathrm{F}(19.0)^{\mathrm{c}}\end{array}$ & $\begin{array}{l}0.59 \\
1.62 \\
\end{array}$ & \multicolumn{8}{|c|}{$\left(\mathrm{n}_{1}-1\right)=2,\left(\mathrm{n}_{2}-1\right)=2,\left(\mathrm{n}_{1}+\mathrm{n}_{2}-2\right)=4$} & \\
\hline
\end{tabular}

a) Average of five determinations; b) Average of three determinations; c) theoretical value.

\section{Analysis of CLP in urine sample}

The proposed method was further applied effectively for estimation of CLP in spiked human urine sample. Two different concentration levels (30 and $40 \mu \mathrm{g} / \mathrm{mL}$ ) were tested for accuracy and precision. Each concentration was analyzed thrice. Acceptable accuracy and precision for urine samples were observed (Table 4).

Table 4. Application of the proposed rFIA method for analysis of CLP in spiked urine samples.

\begin{tabular}{|c|c|c|c|c|}
\hline Sample & Added Conc. $(\mu \mathrm{g} / \mathrm{mL})$ & Found Conc. $(\mu \mathrm{g} / \mathrm{mL})$ & Recovery $(\%)^{*}$ & RSD $(\%)^{*}$ \\
\hline 1 & 30.0 & 28.9 & 96.3 & 0.67 \\
\hline 2 & 40.0 & 37.8 & 94.5 & 0.68 \\
\hline
\end{tabular}

*Average of three determinations.

\section{CONCLUSION}

A few FIA methods were reported for determination of CLP, and most of these methods, were either not sufficiently sensitive or complicated and need expensive instrumentation. From a simple comparison between the proposed method and reported flow injection methods it is evident that the proposed method is characterized by a wider calibration range, high sampling rate. Moreover it was carried out in aqueous medium and did not require any sample pretreatment or conversion.

\section{ACKNOWLEDGMENTS}

The authors are thankful to the Department of Chemistry, College of Science, Baghdad University, for providing facilities. 


\section{REFERENCES}

1. Gilman, A.G.; Goodman, L.S.; Rall, T.W.; Murad, F. Goodman and Gilman's, The Pharmacological Basis of Therapeutics, 10th ed., Mac Millan Publishing Company: New York; 2001.

2. British Pharmacopoeia, The Pharmaceutical Press London: H.M. Stationary Office, UK; 2015.

3. US Pharmacopoeia, US Pharmacopoeial Convention, $29^{\text {th }}$ Rev., National Formulary: Rockville, MD, USA; 2011.

4. Starczewska, B.; Karpinska, J. Application of Eriochrome cyanine R to the extractivespectrophotometric determination of chlorpromazine. Anal. Lett. 1996, 29, 2475-2486.

5. Farhadi, K.; Savojbolaghi, A.K.; Maleki, R. Study of reactions of triiodide and Alizarin red $\mathrm{S}$ with some important phenothiazines. Development of an indirect titrimetric and a spectrophotometric method for the assay of phenothiazine derivatives. J. Chin. Chem. Soc. 2003, 50, 153-159.

6. Nagaraja, P.; Dinesh, N.D.; Gowda, N.M.; Rangappa, K.S. A simple spectrophotometric determination of some phenothiazine drugs in pharmaceutical samples. Anal. Sci. 2000, 16, $1127-1131$.

7. Asghari, A.; Fahimi, E.; Bazregar, M.; Rajabi, M.; Boutorabi, L. Rapid determination of some psychotropic drugs in complex matrices by tandem dispersive liquid-liquid microextraction followed by high performance liquid chromatography. J Chromatogr. B. 2017, 1052, 51-59.

8. Yamini, Y.; Faraji, M. Extraction and determination of trace amounts of chlorpromazine in biological fluids using magnetic solid phase extraction followed by HPLC. J. Pharm. Anal. 2014, 4, 279-285.

9. Mohamed, F.A. Spectrofluorimetric determination of chlorpromazine hydrochloride and thioridazine hydrochloride. Anal. Lett. 1995, 28, 2491-2501.

10. Mohamed, A.M.I.; Abdelmageed, O.H.; Salem, H.; Nagy, D.M.; Omar, M.A. Spectrofluorimetric determination of certain biologically active phenothiazines in commercial dosage forms and human plasma. Luminescence 2013, 28, 345-354.

11. Kojlo, A. Indirect potentiometric determination of chlorpromazine with an oxidative column in a flow injection system. Anal. Lett. 1997, 30, 2353-2363.

12. Sales, M.G.F.; Tomas, J.F.C. Lavandeira, S.R. Flow injection potentiometric determination of chlorpromazine. J. Pharm. Biomed. Anal. 2006, 41, 1280-1286.

13. Belal, F.; El-Ashry, S.M.; Shehata, I.M.; El-Sherbeny, M.A.; El-Sherbeny, D.N. Differential-pulse polarographic determination of some N-substituted phenothiazine derivatives in dosage forms and urine through treatment with nitrous acid. Mikrochim. Acta 2000, 135, 147-154.

14. Wang, R.; Tang, L.Y. Kinetic spectrophotometric method for determination of perphenazine based on monitoring the oxidation intermediate by applying a stopped-flow technique. Spectrochim. Acta A 2005, 61, 791-797.

15. Kojio, A.; Calatayud, J.M. FIA-spectrophotometric determination of N-substituted phenothiazine derivatives by oxidation with a solid-phase reactor of manganese dioxide incorporated in polyester resin beads. Talanta 1995, 42, 909-913.

16. Daniel, D.; Gutz, I.G.R. Spectroelectrochemical determination of chlorpromazine hydrochloride by flow-injection analysis. J. Pharm. Biomed. Anal. 2005, 37, 281-286.

17. Chen, D.; Rios, A.; Decastro, M.D.L.; Valcarcel, M. Simultaneous flow-injection determination of chlorpromazine and promethazine by photochemical reaction. Talanta 1991, 38, 1227-1233.

18. Calatayud, J.M.; Benito, C.G. Photochemical derivatization and spectrofluorimetric determination of chlorpromazine by flow injection. Anal. Chim. Acta 1992, 256, 105-111. 
19. Wang, H.Y.; Xu, G.B.; Dong, S.J. Electrochemiluminescence sensor using tris(2,2'bipyridyl)ruthenium(II) immobilized in Eastman-AQ55D-silica composite thin-films. Anal. Chim. Acta 2003, 480, 285-290.

20. Shi, W.B.; Yang, J.D.; Huang, Y.M. Ion-pair complex-based solvent extraction combined with chemiluminescence determination of chlorpromazine hydrochloride with luminol in reverse micelles. J. Pharm. Biomed. Anal. 2004, 36, 197-203.

21. Jabbar, H.S.; Faizullah, A.T. Flow injection analysis with chemiluminescence detection for determination of two phenothiazines. Int. J. Pharm. Sci. Res. 2015, 6, 474-481.

22. Vinay, K.B.; Revanasiddappa, H.D.; Divya, M.R.; Rajendraprasad, N. Spectrophotometric determination of ofloxacin in pharmaceuticals and human urine. Ecletica Quimica 2009, 34, 65-77.

23. Ruzicka J.; Hansen E.H. Flow injection analysis: Part I. A new concept of fast continuous flow analysis. Anal. Chim. Acta 1975, 78, 145-157.

24. Levie, R. Principles of Quantitative Chemical Analysis, The McGraw-Hill Company, Inc.: Singapore; 1997.

25. Foster, R. Organic Charge-Transfer Complexes, Academic Press: London; 1969.

26. Gouda, A.A.; El Sheikh, R., Amin, A.S.; Ibrahim, S.H. Spectrophotometric methods based on charge transfer complexation reaction for the determination of some antifungal drugs in pure and dosage forms. Bull. Chem. Soc. Ethiop. 2016, 30, 333-346.

27. Gutmann, F.; Kezyer, H. Charge-transfer complexes of chlorpromazine in solution: A conductimetric study. Electrochim. Acta 1967, 12, 1255-1262.

28. Molnar, J.; Foldeak, S.; Nakamura, M.J.; Gaizer, F.; Gutmann, F. The influence of charge transfer complex formation on the antibacterial activity of some tricyclic drugs. Xenobiotica 1991, 21, 309-316.

29. Kolninov, O.V.; Kolesnikova, V.V.; Podsoblyaev, A.P. Study on the mechanism of the radiation-induced chain oxidation of N,N,N,N-tetramethyl-4,4'-diaminodiphenylmethane by tetra bromomethane in poly(vinyl chloride) films. High Energy Chem. 2003, 37, 376-381.

30. Feng, X.D.; Guo, X.Q.; Qiu, K.Y. Study of the initiation mechanism of the vinyl polymerization with the system persulfate/ $\mathrm{N}, \mathrm{N}, \mathrm{N}^{\prime}, \mathrm{N}^{\prime}$-tetramethylethylenediamine, Macromol. Chem. Phys. 1988, 189, 77-83.

31. Young, A.C.; Omatete, O.O.; Janney, M.A.; Menchhofer, P.A. Gelcasting of alumina. J. Am. Ceram. Soc. 1991, 74, 612-618.

32. Miller J.N.; Miller J.C. Statistics and Chemometrics for Analytical Chemistry. Ashford Colour Press Ltd.: Gosport, UK; 2010. 